\title{
Preparation and Characterization of Self-reinforced Paper Using NaOH/thiourea Aqueous Solution at Room Temperature
}

Fuqiang Hu, ${ }^{\text {a }}$ Yucheng Hu, ${ }^{\mathrm{b}}$ Lingling Zhang, ${ }^{\mathrm{a}}$ Meixue Gan, ${ }^{\mathrm{a}}$ Shangjun Liu, ${ }^{\mathrm{c}}$ Yimin Xie, ${ }^{\mathrm{a}, *}$ and Qinghua Feng ${ }^{\mathrm{a}, \mathrm{c}, \mathrm{d}, *}$

The aim of this paper was to enhance paper strength in $\mathrm{NaOH} /$ thiourea aqueous solution at room temperature. Paper from cotton pulp was saturated with room temperature $\mathrm{NaOH}$ /thiourea aqueous solution and placed at a fixed temperature $\left(8,15\right.$, and $\left.20^{\circ} \mathrm{C}\right)$ for a period of time $(1 \mathrm{~h}$, $2 \mathrm{~h}, 4 \mathrm{~h}$, and $6 \mathrm{~h}$ ). The morphology, X-ray diffraction (XRD), mechanical properties, and density of paper were characterized. The results indicated the paper was self-reinforced. Scanning electron microscopy (SEM) photographs indicated that the structure of the treated papers was increasingly compact with decreasing temperature. The XRD results showed that the crystallinity degree of the paper decreased from $80.0 \%$ to $60.0 \%$. The stress at break of the treated papers increased by more than fivefold. The wet tensile strength of the treated papers increased remarkably.

Keywords: Cellulose; Self-reinforced paper; NaOH/thiourea solution; Room temperature

Contact information: a: Hubei Provincial Key Laboratory of Green Materials for Light Industry, Hubei University of Technology, Wuhan 430068, China; $b$ : Collaborative Innovation Center of Green Lightweight Materials and Processing, Hubei University of Technology, Wuhan 430068, China; c: Henan Key Laboratory of Industrial Microbial Resources and Fermentation Technology, Nanyang Institute of Technology, Nanyang 473004, China; : Key Laboratory of Pulp and Paper Science and Technology of Ministry of Education, Qilu University of Technology, Jinan 250353, China;

*Corresponding authors: ppymxie@163.com; fqhpaper@163.com

\section{INTRODUCTION}

Materials from renewable resources are attracting great attention due to the increasing environmental concerns. Cellulose, the most abundant renewable resource in nature (Zhang et al. 2017; Thomas et al. 2018), could be used in fibers (Zhu et al. 2018, 2019), hydrogels (Jiang et al. 2019; Hamedi et al. 2020), aerogels (Olsson et al. 2010; Thai et al. 2020), films (Sadeghifar et al. 2017; Tang et al. 2018; Ye et al. 2019), membranes (Zhang et al. 2016), and bioplastics (Wang et al. 2013; Chen et al. 2018b). In order to satisfy those applications' requirements, the dissolution of cellulose is the pivotal challenge. The traditional cellulose dissolution viscose process, developed over 100 years ago, is widely used for regenerated cellulose (Wang et al. 2016). More recently, some new solvent systems have successfully been developed to dissolve cellulose, which include Nmethylmorpholine-N-oxide (NMMO) (Zhang et al. 2020), ionic liquids (ILs) (Zhang et al. 2019), LiCl/N,N-dimethylacetamide ( $\mathrm{LiCl} / \mathrm{DMAc}$ ) (Ono et al. 2016), $\mathrm{H}_{2} \mathrm{SO}_{4}$ aqueous solution (Huang et al. 2016), $\mathrm{NaOH}$ aqueous solution (Korhonen and Budtova 2019), and $\mathrm{NaOH} /$ urea aqueous solution (Cai and Zhang 2005). 
Cellulose is mainly used in papermaking (Divsalar et al. 2018; Haider et al. 2018; Tanpichai et al. 2019). As one of the essential materials, paper has been commonly used in daily life (Wen et al. 2017). However, the base paper has an inherent low strength property because its main constituent fibers are connected by few hydrogen bonds, which impedes the application in various fields. To meet the needs of the expanding application range, researchers recently utilized cellulose solution to treat paper. Tervahartiala et al. (2018) prepared all-cellulose composites (ACCs) using various commercially available chemical pulps by partial dissolution method using an aqueous zinc chloride $\left(\mathrm{ZnCl}_{2}\right)$ solvent. The results showed high potential of ACCs for corrugated board applications. Ma et al. (2015, 2016) and Jiao et al. (2015) partially dissolved filter paper in zinc chloride solution and $\mathrm{NaOH} / \mathrm{urea} / \mathrm{ZnO}$ aqueous solution to prepare $\mathrm{ZnO}$-cellulose composite paper that exhibited high mechanical strengths, antibacterial property, and grease resistance. Piltonen et al. (2016) made all-cellulose composite (ACC) from sulphite dissolving pulp fibers using a partial dissolution method with $\mathrm{NaOH} /$ urea solvent at $-12{ }^{\circ} \mathrm{C}$. The tensile strength of ACC was 14 times higher than that of the untreated fiber sheet. Zhai and Zhou (2014) pretreated the thermomechanical pulp with a $\mathrm{NaOH} /$ thiourea/urea aqueous solution at $-12{ }^{\circ} \mathrm{C}$ and made paper from the pulp. The paper tensile and burst indices of treated pulp increased nearly $100 \%$. These studies demonstrate great potential in the processing of paper treated with a cellulose solvent. However, $\mathrm{ZnCl}_{2}$ aqueous solution is not desirable from an environmental standpoint due to the presence of heavy metal ions. The $\mathrm{NaOH} /$ urea aqueous solution and $\mathrm{NaOH} /$ thiourea/urea aqueous solution could considerably enhance the strength of paper only under low temperature conditions. Low temperatures are not easily achieved in the paper industry due to significant energy requirement in the process of lowering the temperature.

Cotton, with a cellulose content close to $100 \%$, is frequently used as the base paper, e.g., electrical insulated paper (El-Saied et al. 2012) and integrated paper electrodes (Chen et al. 2018a). As an essential material, paper has great potential for both basic study and sustainable development. Compared with the $\mathrm{NaOH} /$ urea aqueous solution, $\mathrm{NaOH} /$ thiourea aqueous solution, a new cellulose solvent, could dissolve cellulose at room temperature $\left(8^{\circ} \mathrm{C}\right)$ (Jiang et al. 2017). Therefore, the objective of this work was to use the cellulose solvent $(9.3 \mathrm{wt} \% \mathrm{NaOH}: 7.4 \mathrm{wt} \%$ thiourea aqueous solution) to partially dissolve the cellulose in the paper at room temperature, leading to the compact structure and enhance the paper's strength. The treated paper was characterized using scanning electron microscopy (SEM), X-ray diffraction (XRD), and mechanical testing. The impact of thiourea ratio, treatment time, and treatment temperature was discussed in light of these measurements. The schematic diagram for the preparation of self-reinforced paper by $\mathrm{NaOH} /$ thiourea aqueous solution at room temperature can be seen in Fig. 1.

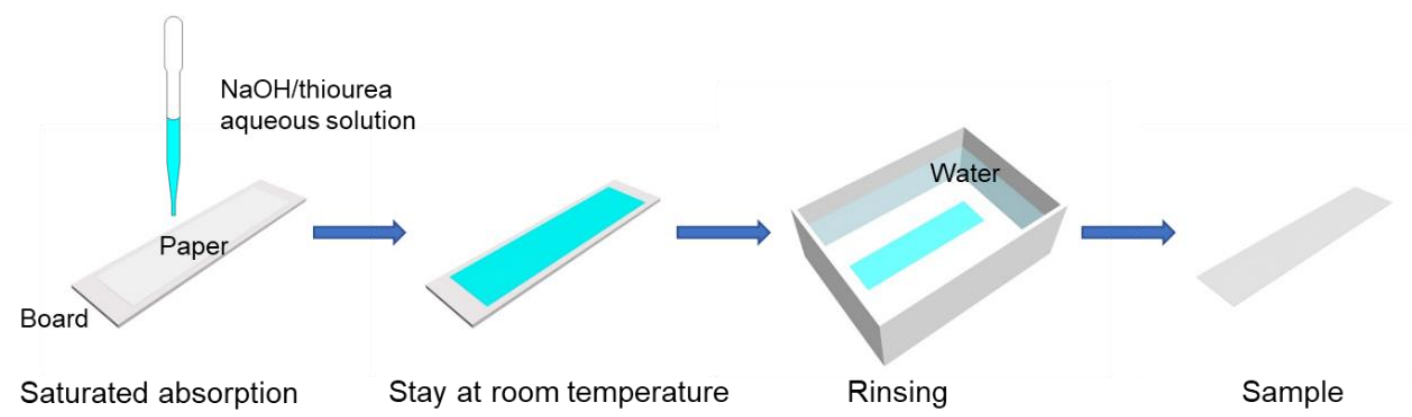

Hu et al. (2020). "Strong paper via green solvent," BioResources 15(4), 8191-8201. 
Fig. 1. Schematic diagram of the procedure for preparing self-reinforced paper EXPERIMENTAL

\section{Materials}

Cellulose (cotton linter pulps) was supplied by Hubei Chemical Fiber Co., Ltd. (Xiangyang, China). Its viscosity-average molecular weight was $4.8 \times 10^{4}$. Sodium hydroxide and thiourea were purchased from Sinopharm Chemical Reagent Co., Ltd. (Shanghai, China). All chemicals were of analytical grade and used as received without further purification.

\section{Preparation of cotton pulp paper}

The cotton pulp was beaten to $28{ }^{\circ} \mathrm{SR}$ by a beater (PL4-00; Xianyang Taist Test Equipment Co., Ltd., Xianyang, China). The quantity of cotton pulp formed into paper using the Rapid-Köthen sheet former (RK-3A, Frank-PTI, Vorchdorf, Austria) was approximately $100 \mathrm{~g} / \mathrm{m}^{2}$. The round-shaped cotton pulp papers were cut into rectangular shape with $16 \mathrm{~cm}$ in length and $4 \mathrm{~cm}$ in width.

\section{Preparation of cotton pulp paper treated with $\mathrm{NaOH} /$ thiourea aqueous solution}

The $\mathrm{NaOH}$ /thiourea aqueous solution was prepared by mixing $\mathrm{NaOH}$, thiourea, and distilled water at room temperature $\left(20{ }^{\circ} \mathrm{C}\right)$. The cotton pulp paper was saturated and adsorbed $\mathrm{NaOH} /$ thiourea aqueous solution on a polypropylene plate. Subsequently, the sample was placed at a fixed temperature $\left(8^{\circ} \mathrm{C}, 15^{\circ} \mathrm{C}\right.$, or $\left.20^{\circ} \mathrm{C}\right)$ for a period of time $(1 \mathrm{~h}$, $2 \mathrm{~h}, 4 \mathrm{~h}$, or $6 \mathrm{~h}$ ). The treated process was halted by immersing the samples in tap water at room temperature. To ensure a complete washing process, the samples needed to be immersed in tap water for $7 \mathrm{~d}$, and the tap water was replaced every $8 \mathrm{~h}$ to obtain the purified paper for further characterization. Finally, the samples were dried in the dryer section of the sheet former.

\section{Methods}

Tensile tests

The stress-strain curves of the samples were conducted with an electromechanical universal testing machine (CMT6103, MTS Industrial Systems (China) Co., Ltd., Shenzhen, China) deployed with a $1 \mathrm{kN}$ load cell and using a strain rate of $3 \mathrm{~mm} / \mathrm{min}$. The samples (60 mm long, $15 \mathrm{~mm}$ wide) was cut and fixed to the tester with a gauge length of $30 \mathrm{~mm}$. The thickness was measured by averaging six random measurement points on each specimen with a thickness gauge (DC-HJY03; Sichuan Changjiang Papermaking Instrument Co., Ltd., Yibin, China). The quality was measured using an electronic balance (GL224-1SCN; Sartorius Scientific Instruments Co., Ltd., Beijing, China). The density was calculated from the quality, length, width, and thickness of paper.

The wet tensile strength values of the samples were measured using a Lorentzen and Wettre (L\&W) tear tester (991178; L\&W, Kista, Sweden). The specimens had a rectangular shape with $138 \mathrm{~mm}$ in length and $15 \mathrm{~mm}$ in width. The samples were strained at a rate of $20 \mathrm{~mm} / \mathrm{min}$ until they broke. The measured data was analyzed according to ISO 1924-3 (2005).

\section{$X$-ray diffraction}

The crystallinity degree of the sample was identified using polycrystal X-ray diffraction (Empyrean, PANalytical B.V., Almelo, Netherlands). The $\mathrm{Cu} \mathrm{K} \alpha$ radiation 
generated at $45 \mathrm{kV}$ and $40 \mathrm{~mA}$ was irradiated on the surface of the samples. Scans were taken over a $2 \theta$ range from $10^{\circ}$ to $40^{\circ}$ at increments of $0.01313^{\circ}$ and a scanning speed $5^{\circ}$ $\min ^{-1}$. The crystallinity degree $(X c, \%)$ was calculated by Eq. 1 (Focher et al. 2001),

$$
X c=A c r /(A c r+A a m) \times 100
$$

where Acr and Aam are the integrated area of the crystalline and amorphous phases, respectively.

\section{Ultra-high resolution cold field scanning electron microscope}

The cross-section and surface of the samples were observed using an ultra-high resolution cold field scanning electron microscope (SEM) (SU8010; HITACHI Ltd., Tokyo, Japan) operated at an accelerating voltage of $5 \mathrm{kV}$. Before imaging, the samples were dried in the dryer section of the sheet former, and then they were coated with gold using the SEM sputter coater (MC1000; HITACHI Ltd., Tokyo, Japan) to improve the sample's electric conductivity. For the cross-section images, the samples were cut with a utility knife before coating.

\section{RESULTS AND DISCUSSION}

\section{SEM}

The morphological changes of paper fibers were observed by SEM. Figure 2 shows SEM images of the cross-section and surface of untreated paper and treated papers at various temperatures. Images of cross-section are identified with lowercase letters. The untreated paper (Fig. 2a) showed a typical loose and porous structure. The treated papers (Fig. 2b, c, and d) changed to a more dense and bound structure with the decrease of temperature.

The morphological changes in the samples indicated that the $\mathrm{NaOH} /$ thiourea system had a great influence on cotton fiber. Moreover, the fiber structure was still clearly visible, which indicated that the dissolution of the fibers did not effectively occur at the treatment temperatures of 20 and $15{ }^{\circ} \mathrm{C}$ (Fig. $2 \mathrm{~b}$ and c). However, at the treatment temperature of $8{ }^{\circ} \mathrm{C}$ (Fig. 2d), few fiber structures were observed. The results indicated that the effect of temperature on the base paper was particularly remarkable, and that $8{ }^{\circ} \mathrm{C}$ was the optimum treatment temperature. This is consistent with the results reported by Dormanns et al. (2016), in which all-cellulose composite laminates treated by $\mathrm{NaOH}$ urea aqueous solution at $-12{ }^{\circ} \mathrm{C}$ exhibited an evenly consolidated cross-section with fewer and smaller cracks than laminates infused at $0{ }^{\circ} \mathrm{C}$. The difference between the treatment temperatures of the $\mathrm{NaOH} /$ thiourea system and $\mathrm{NaOH} /$ urea system could be derived from their optimum cellulose dissolution temperature $8{ }^{\circ} \mathrm{C}$ and $-12^{\circ} \mathrm{C}$, respectively.

Images of surface were labelled with capital letters. The untreated paper (Fig. 2A) showed a rough and porous structure. The structure of the treated papers (Fig. 2B, C, and D) became slightly compact. However, different results were also reported by Ma $e t$ al. (2014), who reported that the paper treated by the $\mathrm{NaOH} /$ urea system showed a highly compact and less porous structure. This could have been attributed to the compressed process of the $\mathrm{NaOH} /$ urea system treated paper. 

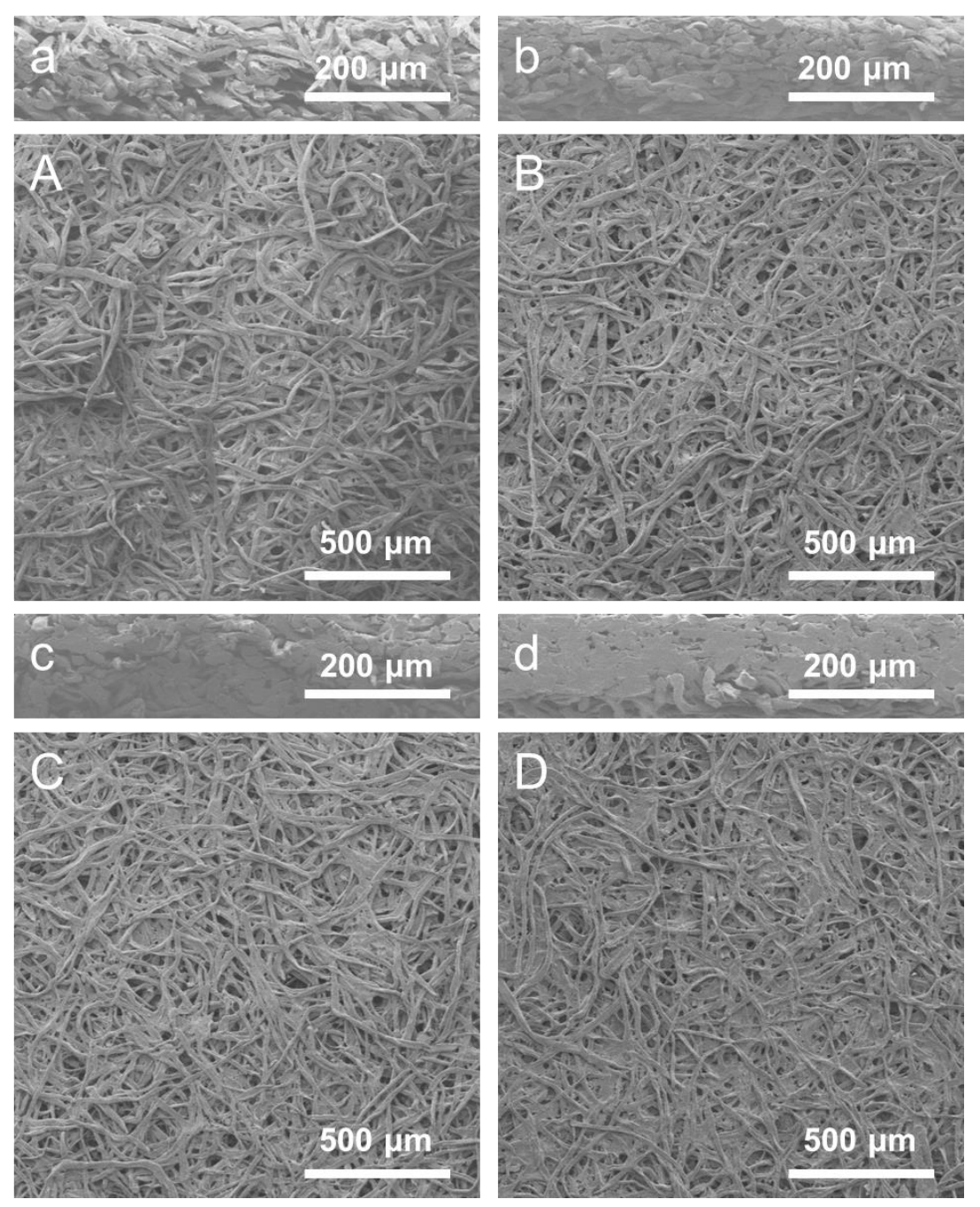

Fig. 2. The SEM pictures of cross-section, surface of untreated paper, and surface of treated papers in $9.3 \mathrm{wt} \% \mathrm{NaOH} / 7.4 \mathrm{wt} \%$ thiourea aqueous solution at various temperatures for $6 \mathrm{~h}$. Pictures with lowercase letters show the cross-section of paper, and the images with capital letters show the surface morphology of paper (Temperatures were as follows: A, a: cotton pulp paper; B, b: $20^{\circ} \mathrm{C} ; \mathrm{C}, \mathrm{c}: 15^{\circ} \mathrm{C}$; $\mathrm{D}, \mathrm{d}: 8^{\circ} \mathrm{C}$ )

\section{XRD}

Figure 3 presents the XRD profiles of the untreated paper and treated papers at various temperatures. In the figure, the untreated paper showed three strong Bragg peaks at $2 \theta=14.6^{\circ}, 16.4^{\circ}$, and $22.6^{\circ}$, which are typical crystalline peaks of cellulose I (Duchemin et al. 2016). The treated paper at various temperatures also had peaks at similar positions, but the peak intensity of the sample decreased with the decrease of temperature.

Figure 3 also shows the crystallinity degree of the untreated paper and treated papers at various temperatures. The crystallinity degree of the untreated paper was $80.0 \%$. As the treatment temperature decreased from $20{ }^{\circ} \mathrm{C}$ to $8{ }^{\circ} \mathrm{C}$, the crystallinity degree was reduced from $76.5 \%$ to $60.0 \%$. This indicated that the $\mathrm{NaOH} /$ thiourea system influenced the crystallinity degree of cellulose paper. A similar trend was observed for self-reinforcing composites from commercial chemical pulps via partial dissolution with $\mathrm{NaOH} / \mathrm{urea}$ (Hildebrandt et al. 2017). 


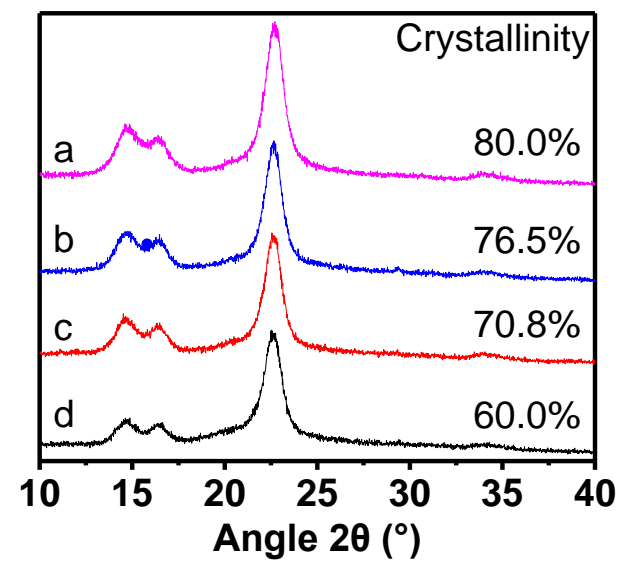

Fig. 3. XRD patterns of the untreated paper (a) and the treated papers in $9.3 \mathrm{wt} \% \mathrm{NaOH} / 7.4 \mathrm{wt} \%$ thiourea aqueous solution at $20^{\circ} \mathrm{C}(\mathrm{b}), 15^{\circ} \mathrm{C}(\mathrm{c})$, and $8^{\circ} \mathrm{C}(\mathrm{d})$ for $6 \mathrm{~h}$

\section{Effect of Treatment Temperature, Thiourea Ratio and Treatment Time on Tensile Properties of Paper}

The stress-strain curves of untreated paper and the treated papers are shown in Fig. 4. The detailed results are summarized in Table 1. Figure 4(a) presents the stress-strain curves of the untreated paper and the treated papers at $8{ }^{\circ} \mathrm{C}$ for various times. The stress at break of the treated papers increased from 9.25 $\mathrm{MPa}$ to $12.39 \mathrm{MPa}$ with the increase of treatment time. The stress at break of the treated paper has more than fivefold compared to the untreated paper from 2.28 MPa to $12.39 \mathrm{MPa}$. The strain at break of the treated paper increased from $1.00 \%$ to $2.35 \%$. However, the strain at break of the untreated paper was $1.79 \%$. The results indicate that the samples were more easily fractured when the treatment time was $1 \mathrm{~h}$ and $2 \mathrm{~h}$. The Young's modulus of the treated papers reduced from 1173 to 986 $\mathrm{MPa}$ with the increase of treatment time. The Young's modulus of the treated papers was remarkably improved compared to the untreated paper. This shows that the treated paper will become more brittle and its stiffness remarkably increased. In summary, the optimal treatment time was $6 \mathrm{~h}$ within the time range set by this experiment.

Figure 4(b) shows the stress-strain curves of the untreated paper and the treated papers at $8{ }^{\circ} \mathrm{C}$ for various thiourea ratio. The stress at break of the treated papers increased from 4.06 $\mathrm{MPa}$ to $12.39 \mathrm{MPa}$ with the increase of thiourea ratio. However, the stress at break of the untreated papers was $2.28 \mathrm{MPa}$. This shows that the thiourea ratio has a great influence on the stress at break of the paper. It can be found that $\mathrm{NaOH}$ alone can increase the stress at break of the paper. It is known from the literature that $\mathrm{NaOH}$ alone can dissolve a small amount of cellulose (Martin-Bertelsen et al. 2020). Therefore, we speculate that the increase in the stress at break of paper may be related to the partial dissolution of cellulose. The strain at break of the treated paper increased from $1.52 \%$ to $2.35 \%$ with the increase of thiourea ratio. The Young's modulus of the treated paper was increased from 404 to $986 \mathrm{MPa}$. This indicates that the thiourea ratio also has a significant effect on the stiffness of the paper. In summary, the optimal thiourea ratio was $7.4 \mathrm{wt} \%$.

Figure 4(c) shows the stress-strain curves of the untreated paper and the treated papers for various temperatures. The stress at break of the treated papers increased from 2.98 to $12.39 \mathrm{MPa}$ with the decrease of treatment temperature. The strain at break was increased from $1.48 \%$ to $2.35 \%$. The Young's modulus was increased from 285 to 986 
MPa. These results are consistent with the results of the SEM and XRD measurements. With the decrease of treatment temperature, the treated paper becomes denser and its crystallinity decreases. This indicates that the bonding between the fibers is positively related to the stress at break of the paper. The bonding of the sample is mainly determined by the partial dissolution of cellulose, which forms more hydrogen bonds. In summary, the optimal treatment temperature was $8{ }^{\circ} \mathrm{C}$. This is consistent with the results reported in the literature that $9.3 \mathrm{wt} \% \mathrm{NaOH} / 7.4 \mathrm{wt} \%$ thiourea aqueous solution could dissolve cellulose at $8{ }^{\circ} \mathrm{C}$ (Jiang et al. 2017).

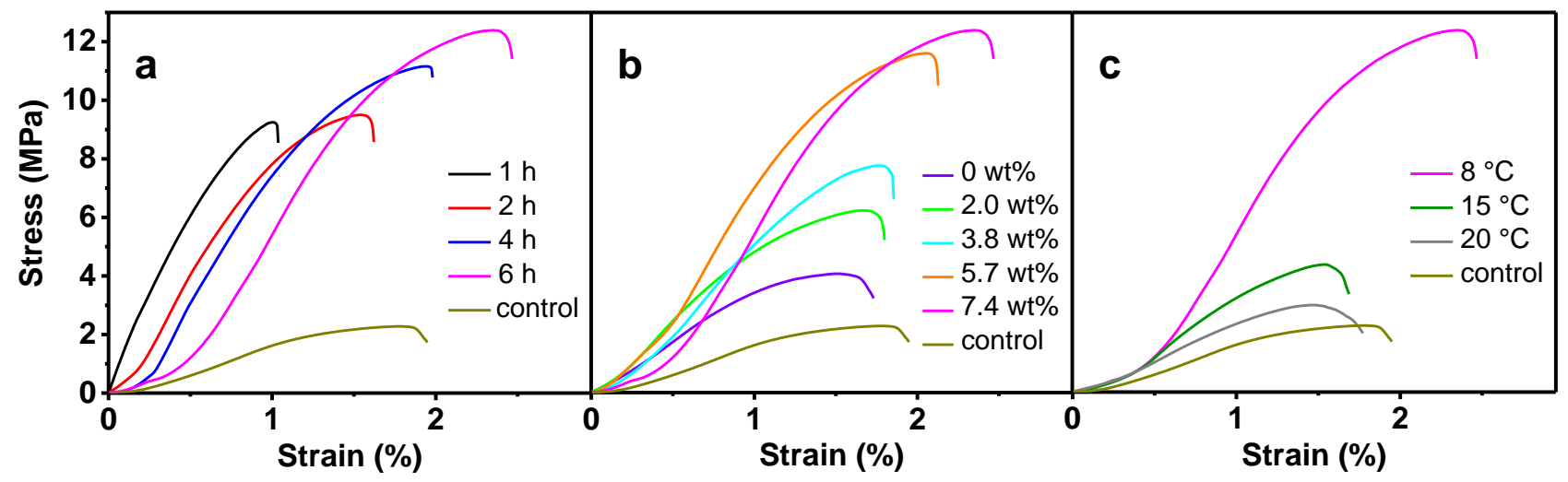

Fig. 4. Stress-strain curves of treated paper: (a) $9.3 \mathrm{wt} \% \mathrm{NaOH} / 7.4 \mathrm{wt} \%$ thiourea aqueous solution at $8{ }^{\circ} \mathrm{C}$ for various times. (b) $9.3 \mathrm{wt} \% \mathrm{NaOH}$ and various thiourea ratio $(0 \mathrm{wt} \%, 2.0 \mathrm{wt} \%, 3.8 \mathrm{wt} \%$, $5.7 \mathrm{wt} \%$, and $7.4 \mathrm{wt} \%$ ) aqueous solution at $8{ }^{\circ} \mathrm{C}$ for $6 \mathrm{~h}$. (c) $9.3 \mathrm{wt} \% \mathrm{NaOH} / 7.4 \mathrm{wt} \%$ thiourea aqueous solution at 20,15 , and $8{ }^{\circ} \mathrm{C}$ for $6 \mathrm{~h}$

Table 1. Mechanical Properties of the Untreated Paper and the Treated Papers in Different Condition

\begin{tabular}{|c|c|c|c|c|}
\hline Effect & Samples & $\begin{array}{c}\text { Stress at Break } \\
(\mathrm{MPa})\end{array}$ & $\begin{array}{c}\text { Strain at Break } \\
(\%)\end{array}$ & $\begin{array}{c}\text { Young's Modulus } \\
(\mathrm{MPa})\end{array}$ \\
\hline \multirow{4}{*}{ Time } & $1 \mathrm{~h}$ & 9.25 & 1.00 & 1173 \\
\cline { 2 - 5 } & $2 \mathrm{~h}$ & 9.50 & 1.54 & 1067 \\
\cline { 2 - 5 } & $\mathrm{4h}$ & 11.16 & 1.94 & 1018 \\
\cline { 2 - 5 } & $6 \mathrm{~h}$ & 12.39 & 2.35 & 986 \\
\hline \multirow{4}{*}{ Thiourea Ratio } & $\mathrm{control}$ & 2.28 & 1.79 & 198 \\
\cline { 2 - 5 } & $0 \mathrm{wt} \%$ & 4.06 & 1.52 & 404 \\
\cline { 2 - 5 } & $2.0 \mathrm{wt} \%$ & 6.23 & 1.66 & 586 \\
\cline { 2 - 5 } & $3.8 \mathrm{wt} \%$ & 7.76 & 1.77 & 645 \\
\cline { 2 - 5 } & $5.7 \mathrm{wt} \%$ & 11.60 & 2.06 & 969 \\
\cline { 2 - 5 } & $7.4 \mathrm{wt} \%$ & 12.39 & 2.35 & 986 \\
\hline \multirow{5}{*}{ Temperature } & $\mathrm{control}$ & 2.28 & 1.79 & 986 \\
\cline { 2 - 5 } & $8{ }^{\circ} \mathrm{C}$ & 12.39 & 2.35 & 465 \\
\cline { 2 - 5 } & $15{ }^{\circ} \mathrm{C}$ & 4.37 & 1.54 & 285 \\
\cline { 2 - 5 } & $20{ }^{\circ} \mathrm{C}$ & 2.98 & 1.48 & 198 \\
\hline
\end{tabular}




\section{Effect of Treatment Temperature on Density and Wet Tensile Strength of Paper}

Table 2 shows the density and wet tensile strength at various temperatures. The results indicated that the density of the treated papers slightly increased with the decrease of treatment temperature. This could be attributed to the increasing compactness of treated paper, as showed in the SEM results. The wet tensile strength of the samples, as shown in Table 2, also increased 2.5 times with the decrease of treatment temperature due to the relatively low temperature favoring cellulose dissolution. The results of wet tensile strength were consistent with the results of stress at break.

Table 2. Density and Wet Tensile Strength of Treated Paper in $9.3 \mathrm{wt} \%$ $\mathrm{NaOH} / 7.4 \mathrm{wt} \%$ Thiourea Aqueous Solution at 20,15 , and $8{ }^{\circ} \mathrm{C}$ for $6 \mathrm{~h}$

\begin{tabular}{|c|c|c|}
\hline Temperature $\left({ }^{\circ} \mathrm{C}\right)$ & $\begin{array}{c}\text { Density }\left(\mathrm{g} / \mathrm{cm}^{3}\right) / \text { Std. Dev. } \\
(\%)\end{array}$ & $\begin{array}{c}\text { Wet Tensile Strength }(\mathrm{N} / \mathrm{m}) / \text { Std. Dev. } \\
(\%)\end{array}$ \\
\hline Control & $0.382 / 0.00284$ & - \\
\hline 20 & $0.387 / 0.00139$ & $62.4 / 0.00283$ \\
\hline 15 & $0.405 / 0.00795$ & $82.1 / 0.00376$ \\
\hline 8 & $0.465 / 0.00892$ & $151.3 / 0.0104$ \\
\hline
\end{tabular}

\section{CONCLUSIONS}

1. The structure of the treated paper was increasingly compact with decreasing temperature of treatment.

2. The crystallinity degree of the paper was also decreased from $80.0 \%$ to $60.0 \%$ with decreased temperature of treatment.

3. The stress at break of the treated paper increased by more than fivefold. The wet tensile strength of the treated papers increased remarkably.

4. The results indicated that the paper treated with $\mathrm{NaOH} /$ thiourea aqueous solution is a promising candidate for packaging products.

\section{ACKNOWLEDGMENTS}

The authors are grateful for Hubei Provincial Universities Outstanding Young and Middle-aged Technological Innovation Team Project (T201205), the Foundation (KF201623) of Key Laboratory of Pulp and Paper Science and Technology of Ministry of Education, Qilu University of Technology, and the Foundation (HIMFT20190204) of Henan Key Laboratory of Industrial Microbial Resources and Fermentation Technology, Nanyang Institute of Technology.

\section{REFERENCES CITED}

Cai, J., and Zhang, L. (2005). "Rapid dissolution of cellulose in LiOH/urea and $\mathrm{NaOH} /$ urea aqueous solutions," Macromol. Biosci. 5(6), 539-548. DOI:

10.1002/mabi.200400222 
Chen, J., Fang, K., Chen, Q., Xu, J., and Wong, C. P. (2018a). "Integrated paper electrodes derived from cotton stalks for high-performance flexible supercapacitors," Nano Energy 53, 337-344. DOI: 10.1016/j.nanoen.2018.08.056

Chen, L., Hou, X., Song, N., Shi, L., and Ding, P. (2018b). “Cellulose/graphene bioplastic for thermal management: Enhanced isotropic thermally conductive property by three-dimensional interconnected graphene aerogel," Compos. Part AAppl. S. 107, 189-196. DOI: 10.1016/j.compositesa.2017.12.014

Divsalar, E., Tajik, H., Moradi, M., Forough, M., Lotfi, M., and Kuswandi, B. (2018). "Characterization of cellulosic paper coated with chitosan-zinc oxide nanocomposite containing nisin and its application in packaging of UF cheese," Int. J. Biol. Macromol. 109, 1311-1318. DOI: 10.1016/j.ijbiomac.2017.11.145

Dormanns, J. W., Schuermann, J., Muessig, J., Duchemin, B. J. C., and Staiger, M. P. (2016). "Solvent infusion processing of all-cellulose composite laminates using an aqueous NaOH/urea solvent system," Compos. Part A- Appl. S. 82, 130-140. DOI: 10.1016/j.compositesa.2015.12.002

Duchemin, B., Le Corre, D., Leray, N., Dufresne, A., and Staiger, M. P. (2016). “Allcellulose composites based on microfibrillated cellulose and filter paper via a $\mathrm{NaOH}$ urea solvent system," Cellulose 23(1), 593-609. DOI: 10.1007/s 10570-015-0835-4

El-Saied, H., El-Meligy, M. G., Mohamed, S. H., and El-Mongy, S. A. (2012). "Electrical insulated paper from cotton linter," Carbohyd. Polym. 90(1), 147-151. DOI: 10.1016/j.carbpol.2012.05.007

Focher, B., Palma, M., Canetti, M., Torri, G., Cosentino, C., and Gastaldi, G. (2001). "Structural differences between non-wood plant celluloses: Evidence from solid state NMR, vibrational spectroscopy and X-ray diffractometry," Ind. Crop. Prod. 13(3), 193-208. DOI: 10.1016/S0926-6690(00)00077-7

Haider, A., Haider, S., Kang, I. K., Kumar, A., Kummara, M. R., Kamal, T., and Han, S. S. (2018). "A novel use of cellulose based filter paper containing silver nanoparticles for its potential application as wound dressing agent," Int. J. Biol. Macromol. 108, 455-461. DOI: 10.1016/j.ijbiomac.2017.12.022

Hamedi, S., Shojaosadati, S. A., Najafi, V., and Alizadeh, V. (2020). "A novel doublenetwork antibacterial hydrogel based on aminated bacterial cellulose and schizophyllan," Carbohyd. Polym. 229, Article ID 115383. DOI: 10.1016/j.carbpol.2019.115383

Hildebrandt, N. C., Piltonen, P., Valkama, J. P., and Illikainen, M. (2017). "Selfreinforcing composites from commercial chemical pulps via partial dissolution with NaOH/urea," Ind. Crop. Prod. 109, 79-84. DOI: 10.1016/j.indcrop.2017.08.014

Huang, W., Wang, Y., Zhang, L., and Chen, L. (2016). "Rapid dissolution of spruce cellulose in $\mathrm{H}_{2} \mathrm{SO}_{4}$ aqueous solution at low temperature," Cellulose 23(6), 3463-3473. DOI: $10.1007 / \mathrm{s} 10570-016-1047-2$

ISO 1924-3 (2005). "Paper and board - Determination of tensile properties - Part 3: Constant rate of elongation method $(100 \mathrm{~mm} / \mathrm{min})$," International Organization for Standardization, Geneva, Switzerland.

Jiang, Y., Zhou, J., Shi, H., Zhao, G., Zhang, Q., Feng, C., and Xv, X. D. (2019). "Preparation of cellulose nanocrystal/oxidized dextran/gelatin (CNC/OD/GEL) hydrogels and fabrication of a CNC/OD/GEL scaffold by 3D printing," J. Mater. Sci. 55, 2618-2635. DOI: 10.1007/s10853-019-04186-0

Jiang, Z., Fang, Y., Ma, Y. P., Liu, M., Liu, R., Guo, H., Lu, A., and Zhang, L. (2017). "Dissolution and metastable solution of cellulose in $\mathrm{NaOH} /$ thiourea at $8{ }^{\circ} \mathrm{C}$ for 
construction of nanofibers," J. Phys. Chem. B 121(8), 1793-1801. DOI:

10.1021/acs.jpcb.6b10829

Jiao, L., Ma, J., and Dai, H. (2015). "Preparation and characterization of self-reinforced antibacterial and oil-resistant paper using a $\mathrm{NaOH} /$ urea/ZnO solution," PLoS One 10(10), e0140603. DOI: 10.1371/journal.pone.0140603

Korhonen, O., and Budtova, T. (2019). "Gelation of cellulose-NaOH solutions in the presence of cellulose fibers," Carbohyd. Polym. 224, Article ID 115152. DOI: 10.1016/j.carbpol.2019.115152

Ma, J., Wang, Z., Zhou, X., and Xiao, H. (2015). "Self-reinforced grease-resistant sheets produced by paper treatment with zinc chloride solution," BioResources 10(4), 82258237. DOI: $10.15376 /$ biores.10.4.8225-8237

Ma, J., Zhou, X., Xiao, H., and Zhao, Y. (2014). "Effect of NaOH/urea solution on enhancing grease resistance and strength of paper," Nord. Pulp Pap. Res. J. 29(2), 246-252. DOI: 10.3183/NPPRJ-2014-29-02-p246-252

Ma, J., Zhu, W., Min, D., Wang, Z., and Zhou, X. (2016). "Preparation of antibacterial self-reinforced zinc oxide-cellulose composite by the synthesis of $\mathrm{ZnO}$ in partially dissolved cellulose," Cellulose 23(5), 3199-3208. DOI: 10.1007/s10570-016-0999-6

Martin-Bertelsen, B., Andersson, E., Köhnke, T., Hedlund, A., Stigsson, L., and Olsson, U. (2020). "Revisiting the dissolution of cellulose in $\mathrm{NaOH}$ as "seen" by X-rays," Polymers 12(2), 342. DOI: 10.3390/polym12020342

Olsson, R. T., Samir, M. A. S. A., Salazar-Alvarez, G., Belova, L. M., Ström, V., Berglund, L., Ikkala, O., Nogues, J., and Gedde, U. W. (2010). "Making flexible magnetic aerogels and stiff magnetic nanopaper using cellulose nanofibrils as templates," Nat. Nanotechnol. 5(8), 584-588. DOI: 10.1038/nnano.2010.155

Ono, Y., Tanaka, R., Funahashi, R., Takeuchi, M., Saito, T., and Isogai, A. (2016). "SEC-MALLS analysis of ethylenediamine-pretreated native celluloses in $\mathrm{LiCl} / \mathrm{N}, \mathrm{N}$ dimethylacetamide: Softwood kraft pulp and highly crystalline bacterial, tunicate, and algal celluloses," Cellulose 23(3), 1639-1647. DOI: 10.1007/s10570-016-0948-4

Piltonen, P., Hildebrandt, N. C., Westerlind, B., Valkama, J. P., Tervahartiala, T., and Illikainen, M. (2016). "Green and efficient method for preparing all-cellulose composites with NaOH/urea solvent," Compos. Sci. Technol. 135, 153-158. DOI: 10.1016/j.compscitech.2016.09.022

Sadeghifar, H., Venditti, R., Jur, J., Gorga, R. E., and Pawlak, J. J. (2017). “Celluloselignin biodegradable and flexible UV protection film," ACS Sustain. Chem. Eng. 5(1), 625-631. DOI: 10.1021/acssuschemeng.6b02003

Tang, Y., Zhang, X., Zhao, R., Guo, D., and Zhang, J. (2018). "Preparation and properties of chitosan/guar gum/nanocrystalline cellulose nanocomposite films," Carbohyd. Polym. 197, 128-136. DOI: 10.1016/j.carbpol.2018.05.073

Tanpichai, S., Witayakran, S., Wootthikanokkhan, J., Srimarut, Y., Woraprayote, W., and Malila, Y. (2019). "Mechanical and antibacterial properties of the chitosan coated cellulose paper for packaging applications: Effects of molecular weight types and concentrations of chitosan," Int. J. Biol. Macromol. 155, 1510-1519. DOI: 10.1016/j.ijbiomac.2019.11.128

Tervahartiala, T., Hildebrandt, N. C., Piltonen, P., Schabel, S., and Valkama, J. P. (2018). "Potential of all-cellulose composites in corrugated board applications: Comparison of chemical pulp raw materials," Packag. Technol. Sci. 31(4), 173-183. DOI: $10.1002 /$ pts. 2365 
Thai, Q. B., Nguyen, S. T., Ho, D. K., Tran, T. D., Huynh, D. M., Do, N. H. N., Luu, T. P. L., Le, P. K., Le, D. K., Phan-Thien, N., et al. (2020). "Cellulose-based aerogels from sugarcane bagasse for oil spill-cleaning and heat insulation applications," Carbohyd. Polym. 228, Article ID 115365. DOI: 10.1016/j.carbpol.2019.115365

Thomas, B., Raj, M. C., Athira, B., Rubiyah, H., Joy, J., Moores, A., Drisko, G., and Sanchez, C. (2018). "Nanocellulose, a versatile green platform: From biosources to materials and their applications," Chem. Rev. 118(24), 11575-11625. DOI: 10.1021/acs.chemrev.7b00627

Wang, Q., Cai, J., Zhang, L., Xu, M., Cheng, H., Han, C., Kuga, S., Xiao, J., and Xiao, R. (2013). "A bioplastic with high strength constructed from a cellulose hydrogel by changing the aggregated structure," J. Mater. Chem. A 1(22), 6678-6686. DOI: 10.1039/C3TA11130J

Wang, S., Lu, A., and Zhang, L. (2016). "Recent advances in regenerated cellulose materials," Prog. Polym. Sci. 53, 169-206. DOI: 10.1016/j.progpolymsci.2015.07.003

Wen, Q., Guo, F., Yang, F., and Guo, Z. (2017). "Green fabrication of coloured superhydrophobic paper from native cotton cellulose," J. Colloid Interface Sci. 497, 284-289. DOI: 10.1016/j.jcis.2017.03.036

Ye, D., Lei, X., Li, T., Cheng, Q., Chang, C., Hu, L., and Zhang, L. (2019). “Ultrahigh tough, super clear, and highly anisotropic nanofiber-structured regenerated cellulose films," ACS Nano 13(4), 4843-4853. DOI: 10.1021/acsnano.9b02081

Zhai, R., and Zhou, X. (2014). "Enhanced effect of NaOH/thiourea/urea aqueous solution on paper strength of high yield pulp," BioResources 9(2), 2154-2166. DOI:

10.15376/biores.9.2.2154-2166

Zhang, J., Kitayama, H., Gotoh, Y., Potthast, A., and Rosenau, T. (2019). "Non-woven fabrics of fine regenerated cellulose fibers prepared from ionic-liquid solution via wet type solution blow spinning," Carbohyd. Polym. 226, Article ID 115258. DOI: 10.1016/j.carbpol.2019.115258

Zhang, W., Chen, X., Pan, J., Gao, C., and Shen, J. (2016). "Preparation and characterization of the tolerance to acid/alkaline and anti-oil-fouling of regenerated cellulose membranes for oil-water separation," RSC. Adv. 6(115), 114750-114757. DOI: $10.1039 / \mathrm{C} 6 \mathrm{RA} 18766 \mathrm{H}$

Zhang, Y., Tian, Z., Fu, Y., Wang, Z., Qin, M., and Yuan, Z. (2020). "Responsive and patterned cellulose nanocrystal films modified by N-methylmorpholine-N-oxide," Carbohyd. Polym. 228, Article ID 115387. DOI: 10.1016/j.carbpol.2019.115387

Zhang, Z., Song, J., and Han, B. (2017). "Catalytic transformation of lignocellulose into chemicals and fuel products in ionic liquids," Chem. Rev. 117(10), 6834-6880. DOI: 10.1021/acs.chemrev.6b00457

Zhu, K., Qiu, C., Lu, A., Luo, L., Guo, J., Cong, H., Chen, F., Liu, X., Zhang, X., and Wang, H., et al. (2018). "Mechanically strong multifilament fibers spun from cellulose solution via inducing formation of nanofibers," ACS Sustain. Chem. Eng. 6(4), 5314-5321. DOI: 10.1021/acssuschemeng.8b00039

Zhu, K., Wang, Y., Lu, A., Fu, Q., Hu, J., and Zhang, L. (2019). “Cellulose/chitosan composite multifilament fibers with two-switch shape memory performance," ACS Sustain. Chem. Eng. 7(7), 6981-6990. DOI: 10.1021/acssuschemeng.8b06691

Article submitted: June 18, 2020; Peer review completed: July 25, 2020; Revised version received: August 4, 2020; Accepted: August 6, 2020; Published: September 10, 2020. DOI: 10.15376/biores.15.4.8191-8201 